\title{
Effectiveness of emamectin benzoate for treatment of Lepeophtheirus salmonis on farmed Atlantic salmon Salmo salar in the Bay of Fundy, Canada
}

\author{
Patti G. Jones*, K. Larry Hammell, Ian R. Dohoo, Crawford W. Revie \\ Centre for Veterinary Epidemiological Research, Department of Health Management, Atlantic Veterinary College, \\ University of Prince Edward Island, Charlottetown, Prince Edward Island C1A 4P3, Canada
}

\begin{abstract}
Emamectin benzoate (an avermectin chemotherapeutant administered to fish as an in-feed treatment) has been used to treat infestations of sea lice Lepeophtheirus salmonis on farmed Atlantic salmon Salmo salar in the Bay of Fundy, New Brunswick, Canada, since 1999. This retrospective study examined the effectiveness of 114 emamectin benzoate treatment episodes from 2004 to 2008 across 54 farms. Study objectives were to establish whether changes in the effectiveness of emamectin benzoate were present for this period, examine factors associated with treatment outcome, and determine variables that influenced differences in L. salmonis abundance after treatment. The analysis was carried out in 2 parts: first, trends in treatment effectiveness and L. salmonis abundance were explored, and second, statistical modelling (linear and logistic regression) was used to examine the effects of multiple variables on post-treatment abundance and treatment outcome. Post-treatment sea lice abundance increased in the later years examined. Mean abundance differed between locations in the Bay of Fundy, and higher numbers were found at farms closer to the mainland and lower levels were found in the areas around Grand Manan Island. Treatment effectiveness varied by geographical region and decreased over time. There was an increased risk for unsuccessful treatments in 2008, and treatments applied during autumn months were more likely to be ineffective than those applied during summer months.
\end{abstract}

KEY WORDS: Emamectin benzoate $\cdot$ Sea lice $\cdot$ Salmo salar $\cdot$ Aquaculture $\cdot$ New Brunswick

\section{INTRODUCTION}

Sea lice are aquatic ectoparasitic copepods of the family Caligidae and feed on the mucus, skin and blood of the host fish. While low level infestations of sea lice cause only minimal effects on the host, high numbers can result in progressively worsening skin damage and even death of the host. As early as 1940, there were reports of high numbers of lice causing severe damage and mortality in wild fish (White 1940). Intensive salmon farming, particularly where fish farms are clustered in regions, can contribute to outbreaks of pathogens and, potentially, to clinical disease (Murray \& Peeler 2005, Robertsen 2011). Lack of adequate control over sea lice populations can result in a number of economic impacts on fish producers. In addition to mortalities related to sea lice infestation and the cost of parasiticides, other factors, such as increased personnel costs, reduction in food conversion efficiency, reduced fish growth and mortalities secondary to treatment, contribute to economic losses (Costello 2009). 
There are 2 genera of sea lice commonly found on salmonids in marine and brackish waters: Lepeophtheirus and Caligus. Major species associated with salmon aquaculture along the east coast of Canada and the USA are L. salmonis and C. elongatus (Boxaspen 2006). L. salmonis is the more pathogenic species in the Bay of Fundy, New Brunswick, Canada, mostly due to its size and aggressive feeding in the later stages of its life cycle. L. salmonis has a 10-stage life cycle with a moult between each stage. There is a free-swimming phase consisting of 2 naupliar and 1 copepodid stages. The copepodid settles on the host fish to begin the attached phase and will then moult through 4 chalimus, 2 pre-adult and 1 adult stage (Johnson \& Albright 1991a, Schram 1993). Johnson \& Albright (1991b) reported the generation time to be $40 \mathrm{~d}$ for adult males and $52 \mathrm{~d}$ for adult females at $10^{\circ} \mathrm{C}$ (time from egg to adult stage).

Salmon farming is a 2 phase production system usually consisting of land-based, freshwater hatchery and marine cage site phases. Fish are transferred from the hatchery as smolts to sea cages, which can occur anywhere from 1 to 2 yr after egg hatching. Fish will be harvested approximately 18 to 24 mo after transfer to sea cages. In New Brunswick, smolts are normally transferred in the spring (April to June) or fall (November to December), and the majority of the fish are transferred during the spring months. Sea lice are a problem during only the marine cage stage of the production cycle.

Emamectin benzoate (SLICE ${ }^{\circledR}$ ) is an avermectin chemotherapeutant administered to fish as an infeed treatment (reviewed by Horsberg 2012). Emamectin benzoate can be effective against Lepeophtheirus salmonis on farmed Atlantic salmon Salmo salar in North America (Armstrong et al. 2000, Gustafson et al. 2006, Saksida et al. 2007). Several studies have examined the efficacy of emamectin benzoate in Maine (USA), Scotland (UK) and British Columbia (Canada) (Gustafson et al. 2006, Lees et al. 2008a,b, Saksida et al. 2010). In Maine, all treatments that were applied appeared to be efficacious; however, the study did not assess changes in effectiveness over the study period of 2002 to 2005 (Gustafson et al. 2006). Examination of emamectin benzoate use in British Columbia found no decrease in effectiveness from 2003 to 2008 (Saksida et al. 2010). A decline in efficacy was reported in Scotland during the years examined, 2002 to 2006 (Lees et al. $2008 a, b)$. On the east coast of Canada, a recent investigation using laboratory bioassays found increases in $\mathrm{EC}_{50}$ (effective concentration) values for emamectin benzoate in L. salmonis from southwestern New Brunswick collected in 2011 (Igboeli et al. 2012) compared with values from 2002 to 2005 (Westcott et al. 2008). A reduction in the sensitivity of Caligus rogercresseyi to emamectin benzoate based on laboratory bioassays has been documented in Chile (Bravo et al. 2008).

In New Brunswick, control of sea lice became a problem in the mid-1990s when there was a consistent increase in the abundance of sea lice found on farmed Atlantic salmon. Initially the majority of sea lice on farmed salmon were Caligus spp., but Lepeophtheirus salmonis later became the predominant species and remains so to the present (Hogans \& Trudeau 1989, Hogans 1995). In the fall of 1994, an outbreak of L. Salmonis occurred on salmon farms in the Lime Kiln and Back Bay areas of southwestern New Brunswick (Hogans 1995). Around that time, a multitude of treatments, including hydrogen peroxide, ivermectin and azamethiphos, were attempted with varying success (Hogans 1995, O'Halloran \& Hogans 1996). Emamectin benzoate was introduced in New Brunswick in 1999 through an emergency drug release (Armstrong et al. 2000). This product became the treatment of choice for several reasons: effectiveness against all life stages, prolonged effect, and ease of administration in feed (Stone et al. 2000a,b). Because emamectin benzoate was an effective treatment, there was little incentive to seek approval for other sea lice treatment agents, resulting in this product being used for the majority of sea lice treatments. After almost a decade of use, isolated treatment failures were observed in late 2008, resulting in suspicions about changes in sea lice sensitivity to emamectin benzoate. During 2009, it became evident that a more serious problem was occurring, which compelled industry and government to investigate other methods of treatment for sea lice (Chang et al. 2011).

The focus of the present study was to examine emamectin benzoate treatment effects on Lepeophtheirus salmonis. The objectives of this retrospective analysis were to establish whether changes in effectiveness of emamectin benzoate were present from 2004 to 2008, examine factors associated with treatment outcome (effective or ineffective), and ascertain which variables influenced differences in post-treatment L. salmonis abundance. A cross section of data obtained from health records collected by salmon farms in the Bay of Fundy region of southwestern New Brunswick from 2004 to 2008 was examined. 


\section{MATERIALS AND METHODS}

\section{Data set}

The Bay of Fundy is located on the east coast of Canada between New Brunswick and Nova Scotia and shares water with Cobscook Bay, Maine, USA (Fig. 1). The area of interest for this study was along the New Brunswick coast of the Bay of Fundy where Atlantic salmon farming represents a major aquaculture activity. A bay management system is used for the location and stocking of fish farms, called Aquaculture Bay Management Areas (ABMA) (Fig. 1). The 8 ABMAs as they were established in 2006 are shown in Fig. 1. In 2010, ABMA 4 was incorporated into ABMA 1, and for the purpose of this study that change was used for all years examined. Data were available from 5 ABMAs (Table 1): (1) Passamaquoddy Bay (including sites around Deer Island and Campobello Island); (2a) Lime Kiln Bay and Back Bay; (3a) the area considered the 'up shore region' heading east towards the city of Saint John (including areas such as Beaver Harbour and Maces Bay); and finally (2b and $3 b) 2$ areas that are both located on the eastern side of Grand Manan Island. These 5 ABMAs contained the majority of active salmon farms. There were no qualifying treatment episodes in ABMAs 5 or 6 , but since

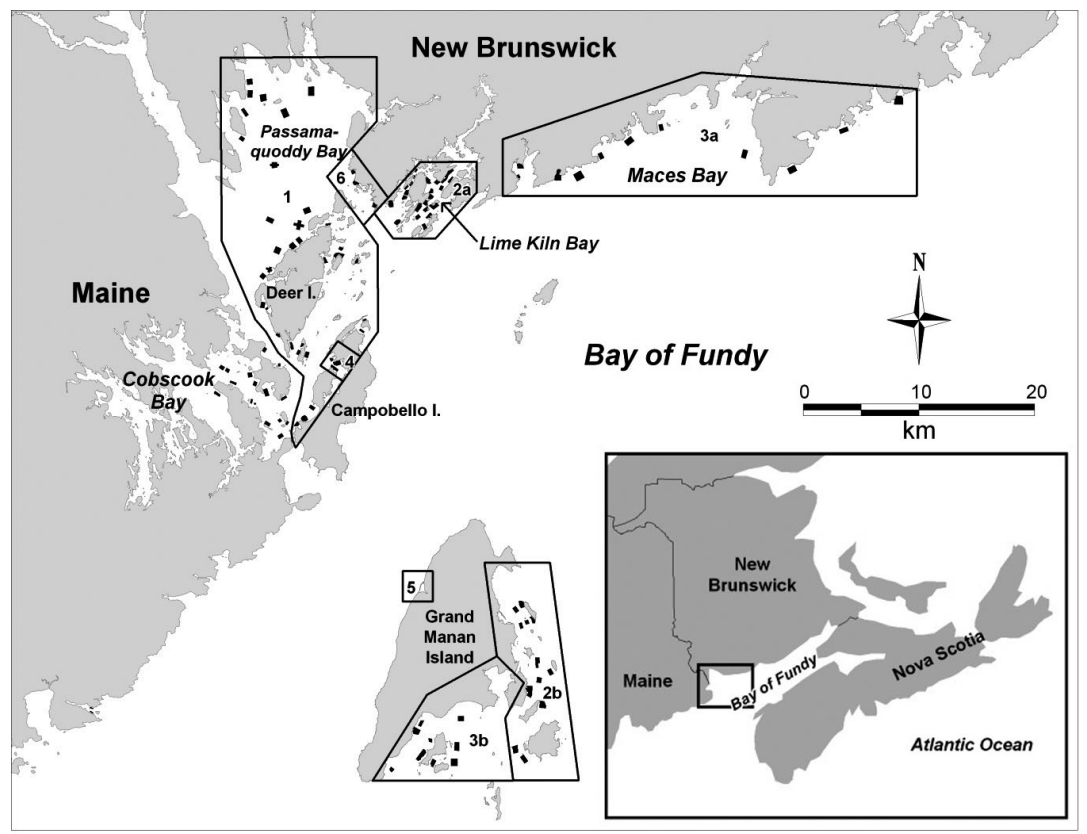

Fig. 1. Aquaculture Bay Management Areas for the southwestern New Brunswick Bay of Fundy salmon farming region (salmon farm leases for 2010 are indicated). Map produced by B. Chang only a few salmon farms are located in these areas, this was not expected to affect this study's conclusions. For part of this analysis (statistical models), ABMAs $2 \mathrm{~b}$ and $3 \mathrm{~b}$, located around Grand Manan Island, were grouped together since they are adjacent to each other and relatively far removed from the other ABMAs.

The data used in this study were extracted from records collected and maintained for sea lice management purposes by the veterinary services within Cooke Aquaculture and Maritime Veterinary Services. These records were associated with just over one-half of the fish farming sites and the majority of the companies operating in this region for the period under examination.

Regular sea lice counts are a routine part of salmon farming in this region, as is the case for most salmon farming areas around the world, and counts typically occur at least every second week. A number of fish are opportunistically sampled by attracting them to the water surface with feed and capturing them with a hand net. Fish are anesthetized in a water bath with tricaine methanesulfonate added, and when fish are sufficiently immobilized the sea lice are counted and classified by using the following life stages: chalimus, pre-adult females, pre-adult males, adult males and adult females (gravid or non-gravid). However, pre-adult males and pre-adult females are often combined with adult males in records to form one category. In this particular study, we examined only Lepeophtheirus salmonis as this is the more pathogenic 
and far more prevalent species found on farmed Atlantic salmon in the Bay of Fundy (Hogans 1995).

\section{Treatment episode selection}

The study design and methodology used in this investigation was similar to methods used in Lees et al. $(2008 \mathrm{a}, \mathrm{b})$ in Scotland. Historical sea lice count data and treatment records were examined from 2004 to 2008 and treatment episodes were selected based on specific study inclusion criteria. To be included, a treatment episode had to contain a pre-treatment count within $16 \mathrm{~d}$ of treatment being started, as well as a minimum of 3 post-treatment sea lice evaluations in the 12 wk after initiation of treatment. If there was more than one pre-treatment count available in the $16 \mathrm{~d}$ period, then the count closest to the date of treatment initiation was used. A specific sea lice count was only included when at least 2 cages were sampled and a minimum of 5 fish per cage were examined. Treatment of sea lice with emamectin benzoate involves the administration of medicated fish feed over the course of $7 \mathrm{~d}$. Any treatment that had a notation in the record regarding only partial site treatment or split-site treatment was excluded from this analysis. For this analysis, pre-adult males, adult males, preadult females and adult females (gravid and nongravid) Lepeophtheirus salmonis were aggregated into a single group called 'total mobiles'.

\section{Treatment trends and effectiveness}

The analysis was split into 2 parts: first, description of treatment effectiveness and trends in Lepeophtheirus salmonis abundance, and second, statistical modelling (linear and logistic regression) to examine the effects of multiple variables on post-treatment mean mobile $L$. salmonis abundance and treatment outcome. For the former, treatment trends were summarized at the farm level and examined by year in 2 ways: first, mean abundance of total mobiles before and after treatment, and second, treatment effectiveness as a percentage of the pre-treatment abundance. Pre-treatment mean abundance of mobile L. salmonis varied by year and this variance was examined by use of an ANOVA procedure. For comparisons of means, a post-ANOVA multiple comparisons procedure was performed using the Bonferroni method. Treatment effectiveness was determined as (post-treatment mean abundance/pre-treatment mean abundance) $\times 100$.
A treatment was considered effective if the posttreatment mean abundance fell to less than $40 \%$ of the pre-treatment mean abundance at any point during the post-treatment period. This value has been used in previous studies as a cut-off point upon which to base treatment success with emamectin benzoate (Lees et al. 2008a,b, Saksida et al. 2010).

\section{Statistical modelling}

The second part of the analysis involved the building of 2 statistical models: a linear model for posttreatment mean mobile Lepeophtheirus salmonis abundance, and a logistic model of treatment effectiveness. Predictor variables used in the building of the statistical models were year, pre-treatment mean mobile L. salmonis abundance, location of farm (ABMA), season, month, season2 (see below), age of fish and season of smolt transfer, as well as the week of count during the post-treatment period. Fish were classified into first or second production year based on the age of fish since their transfer as smolts to ocean cages. Fish were classified as first-year fish if they had been at sea for less than $365 \mathrm{~d}$ and as second-year fish if they were at sea for more than $365 \mathrm{~d}$. Fish were also classified into groups based on the season of smolt transfer, either spring or autumn. Since temperature and season can be important factors in relation to sea lice abundance, the variables month, season and season 2 were created to examine their potential impact on post-treatment L. salmonis abundance. The month of treatment application was used as a predictor, along with a season variable created by categorizing months into the following groups: spring (April to June, 4 to $9^{\circ} \mathrm{C}$ ), summer (July to September, 11 to $14^{\circ} \mathrm{C}$ ), autumn (October to November, 8 to $11^{\circ} \mathrm{C}$ ) and winter (December to March, 1 to $7^{\circ} \mathrm{C}$ ). Water temperatures tend to be highest in August and September $\left(12\right.$ to $\left.14^{\circ} \mathrm{C}\right)$ and lowest in February and March $\left(1\right.$ to $\left.2^{\circ} \mathrm{C}\right)$. Thirdly, a variable, called season2, was created where season was dichotomized based on months where water temperatures were generally above or below $10^{\circ} \mathrm{C}$. Water temperatures were generally above $10^{\circ} \mathrm{C}$ from July to October and below $10^{\circ} \mathrm{C}$ from November to June. For the variable week, the baseline value was Week 2, corresponding to Days 7 to 13 after the start of treatment. Week 1 was eliminated from this part of the analysis because there was usually no noticeable treatment effect at this point (often there was an increase in L. salmonis abundance, as noted in Fig. 2). As mentioned above, for both statistical models, the Grand 
Manan Island ABMAs $2 \mathrm{~b}$ and $3 \mathrm{~b}$ were grouped together (Fig. 1).

For the linear model, upon initial examination of the outcome variable (mean abundance of total mobiles), the data were found to be positively or rightskewed. A Box-Cox analysis produced a lambda value of 0.087 . This led to logarithmic transformation of the data by using the formula $\ln ($ mean +0.1$)$ to help improve our statistical assumptions of normality of residuals and homoscedasticity. Pre-treatment abundance was also logarithmically transformed. Predictor variables were initially screened unconditionally, and those with a p-value of $<0.15$ were retained for model building. The linearity of the relationship between pre-treatment and post-treatment (log) counts was evaluated using a locally weighted scatterplot smoothing algorithm (Lowess) and found to be acceptable. Initially, both treatments and farms were considered random effects, but little unexplained variation was found at the farm level; therefore, a 2-level model (sampling weeks within treatment episodes) was constructed. A Toeplitz covariance structure to account for correlations among counts up to 6 wk apart was applied at the lowest (week) level. Model building was carried out manually and interactions among key variables were evaluated as part of the process. Residuals at both the week and treatment episode level were checked for normality and homoscedasticity.

The second model was a logistic regression model used to evaluate factors associated with treatment success or failure. Success was defined as a minimum of a $60 \%$ reduction in Lepeophtheirus salmonis burdens at any point in the post-treatment period. The outcome variable was treatment success or failure. The predictor variables considered were year, month, season, season2, location (ABMA), fish age, season of smolt transfer and pre-treatment mean L. salmonis abundance (log transformed). A multilevel logistic model using treatments nested within farms was initially assessed but there was little unexplained variation between farms; therefore, a simple logistic regression model was used.

A similar model building process to the linear mixed model was used to create the logistic regression model. The fit of the final model was evaluated by using Hosmer-Lemeshow goodness-of-fit test. Specific observations not fitting the model or having undue influence on the model were evaluated by generating Pearson and deviance residuals, and any outlying values were examined. Influence of outliers on the model was evaluated by generating leverage and deltabeta values.
Software programs used to analyze data were Microsoft Excel 2007 (Microsoft Canada) and Stata/ IC 12 (StataCorp LP). Microsoft Excel 2007 was used to manage and format the data and to create the mean abundance and efficacy graphs. Stata 12 was used to perform the trend and efficacy analysis along with the statistical models.

\section{RESULTS}

After excluding treatment episodes based on study inclusion criteria, 114 treatment episodes across 54 farms remained in this analysis. There was a mean of 40 fish examined per sample (range, 10 to 240) and 4.3 cages selected per sample date (range, 1 to 19 ).

\section{Trends in post-treatment lice abundance and treatment effectiveness}

The pre-treatment mean abundance of mobile Lepeophtheirus salmonis varied over the 5 years examined. In 2004, pre-treatment mean abundance was 0.7 mobiles per fish and increased annually to around 10 times this value by 2007 and 2008 (Fig. 2). Based on an ANOVA procedure, year had a significant $(\mathrm{p}<0.01)$ influence on pre-treatment abundance. Bonferroni multiple comparisons determined that there were significant differences in pre-treatment means between years 2004 and $2007(p=0.001)$ and between 2004 and $2008(\mathrm{p}=0.001)$, as well as between 2005 and 2008 ( $p=0.035$ ). The difference between 2005 and 2007 was marginally significant at $\mathrm{p}=0.056$.

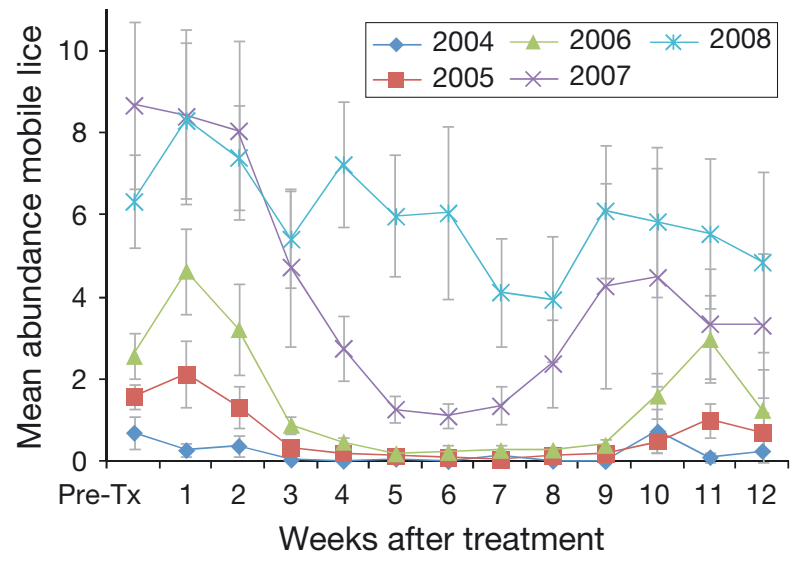

Fig. 2. Mean abundance $( \pm \mathrm{SE})$ of mobile sea lice Lepeophtheirus salmonis before (Pre-Tx) and after treatment with emamectin benzoate on farmed Atlantic salmon in New Brunswick from 2004 to 2008 
Table 2. Summary of qualifying emamectin benzoate treatment episodes for sea lice Lepeophtheirus salmonis by year and number of treatments that were effective or ineffective. Effectiveness was defined as a reduction in lice burden to $<40 \%$ of pre-treatment abundance

\begin{tabular}{|c|c|c|c|}
\hline \multirow[t]{2}{*}{ Year } & \multicolumn{3}{|c|}{ No. of qualifying treatments } \\
\hline & Total & Effective (\%) & Ineffective \\
\hline 2004 & 7 & $7(100)$ & 0 \\
\hline 2005 & 20 & $20(100)$ & 0 \\
\hline 2006 & 23 & $22(95.6)$ & 1 \\
\hline 2007 & 31 & $28(90.3)$ & 3 \\
\hline 2008 & 33 & $17(51.5)$ & 16 \\
\hline Total & 114 & $94(82.5)$ & 20 \\
\hline
\end{tabular}

The number of treatments per year and classification of treatments by success or failure are listed in Table 2. If the post-treatment mean abundance of Lepeophtheirus salmonis fell to less than $40 \%$ of the pre-treatment value at any point during the followup period, then an individual treatment episode was deemed effective. Effectiveness could not be calculated for episodes where pre-treatment abundance was zero and this occurred in 2 treatment episodes, one from 2004 and another from 2008. Both of the treatments resulted in very low L. salmonis abundance in the follow-up period, which ranged from 0 to 0.07 mobiles per fish in all weeks; therefore, these treatments were classified as successful.

Treatment effectiveness declined through the years examined. In 2004 and 2005, all treatments evaluated were deemed effective, while through 2006 to 2008, the number of ineffective treatments progressively increased each year. In 2006, the first ineffective treatment was noted and 2 other treatment episodes were marginally effective (where the maximum effectiveness was $36.9 \%$ and $33.7 \%$ of the mean pretreatment abundance). Overall, 94 of 114 treatment episodes, or $82 \%$, were classified as effective for all the years examined. The major change occurred between 2007 and 2008 when the percentage of successful treatments decreased from 90 to $51 \%$.

In 2007, 28 of 31 treatments were deemed effective in this study, although only 20 treatments reached a post-treatment abundance level of $<1$ mobile per fish. In 2008, 17 of the 33 treatments were considered effective based on the cut-off point of $40 \%$; however, only 14 of these treatments reached post-treatment abundance of $<1$ mobile per fish.

The effectiveness of emamectin benzoate summarized by year as a percentage of pre-treatment mean abundance of Lepeophtheirus salmonis is demonstrated in Fig. 3. All years, on average, exhibited overall treatment success, except for 2008. However, the maximum level of effectiveness attained decreased with each subsequent year. In 2004, the posttreatment mean abundance fell to as low as $0.9 \%$ of pre-treatment levels during the follow-up period, while in 2005, maximum effectiveness was $6.8 \%$ of the pre-treatment level. This effectiveness continued to erode over the next 3 yr (15.3\% for 2006, $22.6 \%$ for 2007 and $75.7 \%$ for 2008 ).

Duration of treatment effect varied between treatment episodes, but in this study it appeared to last approximately 9 to $10 \mathrm{wk}$ during the early years (Fig. 3). In 2004 and 2005, the trends were typical for an effective treatment with emamectin benzoate when the percentage of pre-treatment levels decreased to less than $20 \%$ by Week 3 and remained relatively low for the following $7 \mathrm{wk}$. In 2006, there was an expected drop in mobile Lepeophtheirus salmonis following treatment, but effectiveness values did not stay low for as long as those seen in 2004 and 2005 as evidenced by an increase that began around Week 8 after 2 to 3 wk of minimum values. By 2007, there appeared to be a steady rise in values beginning around Week 6 or 7 after treatment. The dramatic drop previously observed in the first few weeks after treatment was absent in 2008. Although just over $50 \%$ of treatment episodes were deemed effective, treatments as a whole for that year were classified as ineffective; this is evident in the failure to drop below $75 \%$ in 2008 on Fig. 3. Overall, duration of treatment effect appeared to decrease with time.

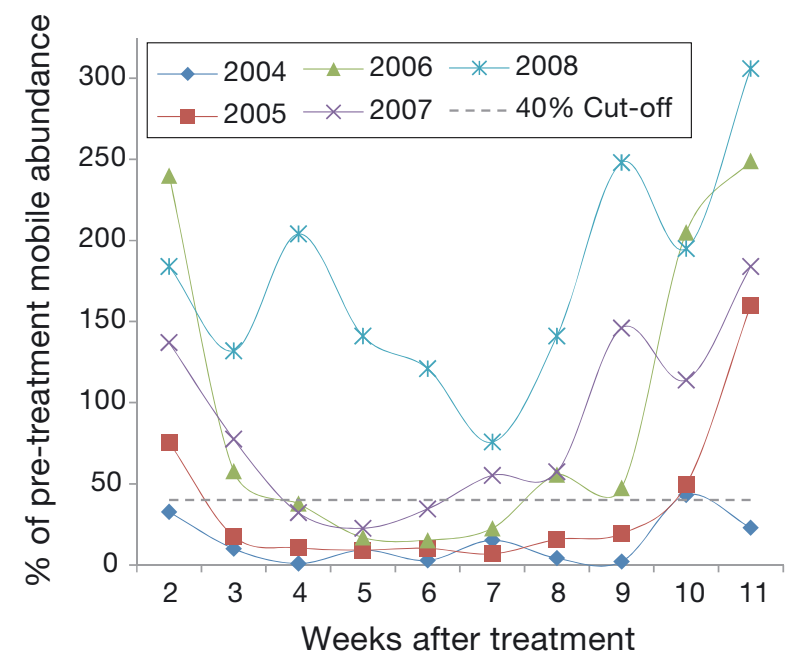

Fig. 3. Trends in treatment effectiveness (as a percentage of pre-treatment mean abundance of mobile sea lice) of emamectin benzoate treatments against Lepeophtheirus salmonis on farmed Atlantic salmon in New Brunswick from 2004 to 2008 
Time to maximum effectiveness varied by treatment episode and year. In the early years, maximum treatment effect was generally attained between Weeks 4 and 6 after the start of treatment (Fig. 3). The time to maximum effect was extended to Week 7 in the final year of the study (2008).

\section{Statistical modelling of post-treatment lice abundance}

The linear mixed model was evaluated initially using a 3-level model in which weeks were nested within treatments and treatments were nested within farms. There were 114 treatments spread over 54 farms resulting in a mean of 2.1 treatments per farm (range was 1 to 5). We determined that the use of farm as a random effect was not necessary given there was little unexplained variation at the farm level, probably because there were so few treatments per farm. As a result, a 2-level model was used with weeks nested within treatments. Treatment episodes were treated as random effects. In the 2-level model, there was little unexplained variation at the treatment level as all the variation was explained by both the fixed parameters and the unexplained variation by the covariance pattern (Toeplitz correlation structure) at the lowest level (week). The covariance estimates confirmed that there was a high level of correlation among counts collected close together (1 to $2 \mathrm{wk}$ apart), but that this declined steadily and there was no remaining correlation once counts were more than $6 \mathrm{wk}$ apart.

Table 3. Results of the linear mixed regression model of mean mobile sea lice Lepeophtheirus salmonis abundance (log transformed) after treatment with emamectin benzoate at Atlantic salmon farms in New Brunswick from 2004 to 2008. Baseline values are: Year: 2004; Bay code: Passamaquoddy (1); Season of transfer: spring; Fish age: <1 yr; Week: 2

\begin{tabular}{|c|c|c|c|c|c|c|}
\hline \multirow[t]{2}{*}{ Variable } & \multirow[t]{2}{*}{ Category } & \multirow{2}{*}{$\begin{array}{l}\text { Coefficient (log- } \\
\text { transformed) }\end{array}$} & \multirow[t]{2}{*}{$\mathrm{SE}$} & \multirow[t]{2}{*}{$\mathrm{p}$} & \multicolumn{2}{|c|}{$-95 \% \mathrm{CI}$} \\
\hline & & & & & Lower & Upper \\
\hline \multirow[t]{4}{*}{ Year } & 2005 & 0.10 & 0.32 & 0.759 & -0.53 & 0.73 \\
\hline & 2006 & 0.30 & 0.32 & 0.354 & -0.33 & 0.93 \\
\hline & 2007 & 0.86 & 0.33 & 0.010 & 0.21 & 1.51 \\
\hline & 2008 & 1.60 & 0.34 & 0.000 & 0.94 & 2.26 \\
\hline \multirow[t]{3}{*}{ Bay code (ABMA) } & Lime Kiln (2a) & -0.41 & 0.24 & 0.087 & -0.87 & 0.06 \\
\hline & Grand Manan (2b and 3b) & -1.09 & 0.18 & 0.000 & -1.45 & -0.73 \\
\hline & Maces Bay (3a) & -0.38 & 0.20 & 0.061 & -0.78 & 0.02 \\
\hline \multirow[t]{10}{*}{ Week } & 3 & -0.66 & 0.07 & 0.000 & -0.81 & -0.52 \\
\hline & 4 & -0.90 & 0.09 & 0.000 & -1.08 & -0.72 \\
\hline & 5 & -1.15 & 0.10 & 0.000 & -1.36 & -0.95 \\
\hline & 6 & -1.22 & 0.12 & 0.000 & -1.46 & -0.97 \\
\hline & 7 & -1.23 & 0.13 & 0.000 & -1.48 & -0.98 \\
\hline & 8 & -1.07 & 0.14 & 0.000 & -1.34 & -0.80 \\
\hline & 9 & -0.80 & 0.15 & 0.000 & -1.09 & -0.51 \\
\hline & 10 & -0.46 & 0.15 & 0.000 & -0.76 & -0.16 \\
\hline & 11 & -0.26 & 0.16 & 0.111 & -0.57 & 0.06 \\
\hline & 12 & -0.07 & 0.18 & 0.686 & -0.43 & 0.28 \\
\hline Season of transfer & Autumn & 0.16 & 0.28 & 0.572 & -0.39 & 0.70 \\
\hline Fish age & $>365 \mathrm{~d}$ & 0.28 & 0.16 & 0.076 & -0.03 & 0.60 \\
\hline Fish age $\times$ season of $\operatorname{tr}$ & action & 0.84 & 0.32 & 0.009 & 0.21 & 1.47 \\
\hline Pre-treatment abunda & nsformed) & 0.44 & 0.06 & 0.000 & 0.32 & 0.55 \\
\hline Constant & & -0.42 & 0.33 & 0.200 & -1.06 & 0.22 \\
\hline \multirow{2}{*}{\multicolumn{2}{|c|}{ Random effects parameters }} & Estimate & SE & & \multicolumn{2}{|c|}{$95 \% \mathrm{CI}$} \\
\hline & & & & & Lower & Upper \\
\hline Treatment: identity & Variance (constant) & $1.26 \times 10^{-15}$ & & & & \\
\hline \multirow[t]{7}{*}{ Residual: Toeplitz (6) } & Covariance1 & 0.76 & 0.07 & & 0.62 & 0.91 \\
\hline & Covariance2 & 0.61 & 0.07 & & 0.48 & 0.74 \\
\hline & Covariance3 & 0.47 & 0.06 & & 0.35 & 0.58 \\
\hline & Covariance4 & 0.30 & 0.05 & & 0.20 & 0.39 \\
\hline & Covariance5 & 0.22 & 0.04 & & 0.14 & 0.29 \\
\hline & Covariance6 & 0.10 & 0.03 & & 0.05 & 0.15 \\
\hline & Variance (e) & 0.98 & 0.07 & & 0.84 & 1.14 \\
\hline
\end{tabular}


Results of the linear mixed model are shown in Table 3 as the log-transformed values. Results showed that post-treatment mean Lepeophtheirus salmonis abundance increased during the later years of the study and significant differences were found between 2004 and 2007 and between 2004 and 2008 . No significant differences were found between posttreatment L. salmonis levels in ABMA 1 (Passamaquoddy Bay) and ABMA 2a (Lime Kiln Bay) or between ABMA 1 and ABMA 3a (Maces Bay). Levels of L. salmonis abundance were significantly lower at sites near Grand Manan Island (ABMAs 2b and 3b) than at sites in Passamaquoddy Bay (ABMA 1).

Pre-treatment mean abundance of Lepeophtheirus salmonis was a significant predictor in the level of abundance during the post-treatment period. For every increase in the pre-treatment abundance of 1 natural log value (equivalent to an increase by a factor of 2.7 times), there was a corresponding increase in the post-treatment log-values of 0.44 (equivalent to an increase by a factor of $\sim 1.5$ times).

There was a significant interaction between age of fish and season of smolt transfer indicating that the effects of fall transfer were different in second-year fish compared with first-year fish. Ultimately, fish in their second year and transferred to seawater in the fall were more likely to have higher post-treatment Lepeophtheirus salmonis abundance than secondyear fish that were transferred in the spring.

\section{Statistical modelling of treatment outcome}

A logistic regression model examined factors involved with treatment outcome, classified as either effective or ineffective treatments (Table 4). Since there were no ineffective treatment episodes found in either 2004 or 2005, those years were dropped from this component of the analysis. The spring season was also dropped as it contained only 4 treatment episodes (1 in 2006 and 3 in 2008), none of which were classified as ineffective. Based on the exclusion of the episodes from these years and season, a total of 83 treatment episodes were evaluated, which led to a mean of 1.8 treatments per farming site.

Location of treatment was not significant in the full model. However, the model was unable to estimate the effect of predictor variables on treatment failure in ABMAs 2b or 3b (Grand Manan Island) as there were no failed treatments in the data set, even in 2008. There appeared to be no significant differences in treatment outcome between ABMAs 1, 2a and 3a. All possible interactions between variables were evaluated during the model-building process and none were found to be significant. Fit of the model to the data was evaluated by use of the Hosmer-Lemeshow goodness-of-fit test; there was no evidence of lack of fit. All potentially influential observations or outliers were assessed and examined, and none were found to have undue influence on the model.

In summary, this model showed that treatments applied in 2008 had an increase in the odds of failure by 37 times over a treatment applied in the year 2006 . Season was also a significant variable ( $p<0.01$ ); treatments administered during autumn (October and November) had an odds of failure approximately 7 times that of treatments applied during summer months (July to September).

\section{DISCUSSION}

There are challenges commonly encountered when using historical production data, some of which were reviewed by Lees et al. (2008a). The challenges encountered in the present study were that numerous individuals carried out the sea lice counts (lack of consistency), pre-treatment counts occurred any time within the $16 \mathrm{~d}$ period prior to treatment initiation (true pre-treatment levels at treatment initiation may have been higher than indicated) and treatment episodes were excluded that did not meet the inclu-

Table 4. Results of logistic regression analysis of factors associated with ineffective emamectin benzoate treatments for sea lice Lepeophtheirus salmonis at salmon farms in New Brunswick from 2006 to 2008. Constant is baseline year 2006 in the summer season

\begin{tabular}{|c|c|c|c|c|c|c|c|}
\hline Variable & Category & Coefficient & SE & $\mathrm{p}$ & Odds ratio & $\begin{array}{l}-95^{\circ} \\
\text { Lower }\end{array}$ & $\begin{array}{l}\% \text { CI- } \\
\text { Upper }\end{array}$ \\
\hline \multirow[t]{2}{*}{ Year } & 2007 & 1.02 & 1.23 & 0.407 & 2.78 & 0.25 & 31.22 \\
\hline & 2008 & 3.63 & 1.18 & 0.002 & 37.64 & 3.72 & 380.22 \\
\hline Season & Autumn & 1.97 & 0.74 & 0.008 & 7.18 & 1.67 & 30.92 \\
\hline Pre-treatment abundance $[\ln (x+0.1)]$ & & -0.24 & 0.26 & 0.357 & 0.79 & 0.47 & 1.31 \\
\hline Constant & & -3.91 & 1.15 & 0.001 & & & \\
\hline
\end{tabular}


sion criteria. The use of a large data set helped to improve the statistical power of this study. The data set used in the present study was comparable in size to that used by Lees et al. $(2008 a, b)$ but larger than those used in similar previously published studies (Gustafson et al. 2006, Saksida et al. 2010).

A concern with the use of historical data is the lack of control groups as discussed in Gustafson et al. (2006). Classic assessment of treatment efficacy involves a study design in which the effect of treatment is based on the differences between 2 groups randomized to treatment or control, such as attempted by Campbell et al. (2006). In the treatment of parasite populations in the aquatic environment where disease progression is best controlled while in the early stages, there are welfare concerns when leaving cages of fish untreated with a growing sea lice infestation. To assess the treatment effectiveness of emamectin benzoate in a clinical environment that was not amenable to the inclusion of untreated control cages, treatment effects had to be based on the change in sea lice populations after treatment compared with the pre-treatment sea lice assessments.

This study relied on sea lice count data recorded by the fish farmers whose routine management required frequent enumeration of sea lice on Atlantic salmon. Although fish are obtained using non-random samples (i.e. attracting fish to the surface with feed and then capturing them with a hand net) and sampling bias may have been introduced, there are no practical solutions for frequent random samples in the salmon farming environment. Sampling practices have been reviewed in a number of studies (Revie et al. 2005, 2007, Heuch et al. 2011) and can be a precise method for detection of farm level sea lice infestations. In field observational studies of sea lice patterns, any selection bias associated with estimates of the true mean sea lice abundance is assumed to be present in similar levels across different treatment events and thus inconsequential to the interpretation of effectiveness.

In this study, pre-treatment Lepeophtheirus salmonis abundance in the early years was lower than the pre-treatment abundance in similar studies. In Lees et al. (2008a), the pre-treatment mean L. salmonis abundance ranged from approximately 5 to 15 mobiles per fish, while in Saksida et al. (2010) the range was from approximately 4 to 7 mobiles per fish. In the present study, pre-treatment values were, on average, fewer than 3.0 mobiles per fish for 2004 to 2006, but in 2007 and 2008 they rose to 8.7 and 6.3 mobiles per fish, respectively. The reason for this change in pre-treatment $L$. salmonis abundance between
2004-2006 and 2007-2008 cannot be determined with this study design. This observation may be associated with increased L. salmonis tolerance for emamectin benzoate (unable to maintain sufficient control over populations), natural variation in the levels of $L$. salmonis found on farmed fish in that region or a tendency by farm management to initiate treatment decisions differently. Lees et al. (2008a) also observed differences in pre-treatment abundance between years with higher abundance occurring in 2003 and 2004.

During the early years of the present study, duration of treatment effect appeared to last for approximately 9 to 10 wk after treatment initiation. Similarly, Lees et al. (2008a) found the lowest Lepeophtheirus salmonis abundance between Days 21 and 62 (Weeks 4 and 9), with levels generally remaining below pre-treatment levels for the full observation period (83 d). We found the length of treatment effect was reduced in later years. Development of tolerance in L. salmonis to this compound may have been a factor, but one cannot rule out other possible variables, such as increases in external infection pressure, seasonal effects or lack of data in the later weeks of some treatment episodes. Recent laboratory bioassay evidence is suggestive of the development of decreased sensitivity to emamectin benzoate in L. salmonis from the Bay of Fundy over time (Igboeli et al. 2012). In British Columbia, an assessment of emamectin benzoate efficacy found that acceptable levels of posttreatment abundance were maintained for at least 3 mo following treatment, with $L$. salmonis levels remaining significantly below pre-treatment levels as well as staying below the trigger level of ' 3 mobile L. salmonis per fish' used in British Columbia (Saksida et al. 2010). The reason for this continued success of emamectin benzoate treatments in British Columbia is unknown, but may be influenced by the large populations of wild Pacific salmon, which may act as a refuge for sea lice sensitive to emamectin benzoate. In addition, there are differences in how farms are distributed between these areas; farms in British Columbia are located over a larger area, while in southwestern New Brunswick farms are more densely concentrated in a smaller region. These differences may play a role in the variation of L. salmonis sensitivity between these 2 regions and warrant further investigation.

Results for time to maximum effectiveness were similar to those in other studies. In Lees et al. (2008a), the lowest levels were found around Days 28 to 34 (Week 5) in the early years of the study, while Gustafson et al. (2006) found a similar range of 21 to 
$28 \mathrm{~d}$ (Week 4) for the maximum effect to be reached. Maximum effectiveness was, on average, attained between Weeks 4 and 6 from 2004 to 2007. In 2008, maximum treatment effect was not evident until Week $7(75.7 \%)$. These trends were supported by clinical observations that Lepeophtheirus salmonis were remaining on fish longer after treatment administration when suspicions of tolerance development first emerged (M. Moore pers. comm.).

The major finding from the results of the linear mixed model for variables associated with post-treatment mean abundance of Lepeophtheirus salmonis was that treatment effect varied both temporally and spatially. Post-treatment abundance increased from 2004 to 2008. In addition, there were differences by location, and the areas farthest from the mainland at Grand Manan Island (ABMAs $2 b$ and $3 b$ ) had the lowest $L$. Salmonis burdens. Similar findings were reported by Lees et al. (2008a). Variables related to month or season of treatment application were nonsignificant. The majority of treatment episodes (97 of 114 ) in this analysis occurred between July and October; consequently there were insufficient treatment episodes spread throughout the year to support conclusions on the effects of season on post-treatment abundance. Only one treatment met the inclusion criteria during the winter season (December to March) and this was an effective treatment in 2004. One could speculate that we would expect to see overall lower L. salmonis abundance around treatment episodes during the winter months as sea lice levels in New Brunswick tend to be lowest throughout the winter (Chang et al. 2011). However, time to maximum treatment effect may be delayed in winter, as was shown in an efficacy study on emamectin benzoate that found treatments applied during colder months took longer to reach maximum effect (Stone et al. 2000c). In comparison, Lees et al. (2008a) found some seasonal variations in the Scottish data in posttreatment levels in which treatments applied during winter (November to January) and spring (February to April) had higher abundance of L. Salmonis.

The frequency of treatments in young versus older fish was almost equivalent with 59 treatments being administered to fish less than $1 \mathrm{yr}$ in sea cages and 55 treatments applied to fish having been in seawater for more than $1 \mathrm{yr}$. In New Brunswick, the majority of salmon smolts are transferred in spring as opposed to fall, and this was reflected in the data. Of the 114 treatments, 88 were applied to springtransferred fish. In our analysis, the quantity of posttreatment Lepeophtheirus salmonis abundance in second-year fish depended upon whether these fish were transferred in spring or fall. For example, in 2008, second-year fish had a notable increase in modelled post-treatment abundance between spring and fall transfers, which went from 1.89 to 5.31 mobile $L$. salmonis per fish (for the sixth week following treatment initiation in year 2008 in Passamaquoddy Bay). There may be other explanatory factors contributing to the significance of this interaction that have not been explored in this study, such as the use of emamectin benzoate in the freshwater hatchery phase prior to transfer, proximity of other farms treating for sea lice, variation in fish size or the inability to administer treatments due to inclement weather. A linear regression model was also used by Lees et al. (2008a) who similarly found that post-treatment L. salmonis abundance was higher in second-year fish. In general, L. salmonis abundance can be higher during the second year of production at sea (Saksida et al. 2007, Lees et al. 2008c).

In the logistic model, pre-treatment Lepeophtheirus salmonis abundance was forced into the model due to the potential of being a confounding variable. However, pre-treatment abundance was found to be nonsignificant, indicating that pre-treatment levels did not appear to be a determining variable for treatment outcome. If a treatment was going to be unsuccessful, it was going to happen regardless of $L$. salmonis abundance prior to treatment application. A similar result was found by Lees et al. (2008b) when they examined the Scottish data. Likewise, Lees et al. (2008b) found year and season to be significant variables in the logistic model with an increased risk of ineffective treatments occurring with time, and the most marked increase was noted for the last year examined (2006) in the Scottish data. In New Brunswick, a notable increase in risk of failed treatments occurred in the last year of the study (2008). Furthermore, autumn treatments were at significant risk of failure compared with treatments applied during the summer months. Again, there were insufficient data available to evaluate the effects of season on treatments applied during winter or spring months.

This study found that ineffective treatments occurred in all bays except those around Grand Manan Island (ABMAs 2b and $3 \mathrm{~b}$ ). Grand Manan Island is located $32 \mathrm{~km}$ south of Blacks Harbour, New Brunswick. The closest mainland is the easternmost point of Maine in the USA, close to the town of Lubec, which is $15 \mathrm{~km}$ across the Grand Manan Channel (see Fig. 1). Given the location, sea farms in this area would be more exposed to the open ocean than other locations closer to the New Brunswick 
mainland. These fish are exposed to different environmental variables (farm density, tidal excursion, current speeds), which may have resulted in lower sea lice infection pressure than fish on farms close to the New Brunswick mainland (Chang et al. 2011). Farms in this region are physically farther away from farms closer to the mainland and perhaps the resistant sea lice had not migrated that far between farms, or resistance had not yet developed locally from repeated treatments leading to selection of emamectin-resistant sea lice. There were more qualifying treatment episodes on farms located in bays closer to mainland New Brunswick (72 treatments in ABMAs 1 and 2a versus 22 treatments in ABMAs 2b and $3 b$ ). Because there were fewer treatments applied around Grand Manan Island, there may have been decreased selection pressure (i.e. selection of resistant sea lice) in comparison with other areas. Increased frequency of pesticide application is one of the factors associated with development of parasiticide resistance (Denholm et al. 2002).

The underlying cause of ineffective treatments cannot be determined from this analysis. In the available treatment records reviewed for this study, emamectin benzoate was found to account for $>95 \%$ of sea lice treatments applied from 2004 to 2008. Although resistance to emamectin benzoate could be the primary cause for treatment failure, other reasons for reduced treatment efficacy, such as poor feed ingestion by fish, improper application (not feeding for full $7 \mathrm{~d}$ or missed treatment days due to inclement weather) or inappropriate concentration or distribution of the drug within the feed may all contribute to subtherapeutic dosing and potentially lead to isolated treatment failures. Treatment failures can lead to erroneous conclusions of resistance development. In an effort to substantiate suspicions of a decay in treatment effectiveness, this study employed epidemiological principles and a relatively large sample size encompassing both time and location to investigate this issue. Evidence presented in this study shows a decline in treatment effectiveness, which is suggestive of resistance development.

Changes in susceptibility of sea lice to emamectin benzoate have been assessed by other methods, of which the most common approach is the bioassay. Bioassays have been used in New Brunswick (Westcott et al. 2008), as well as in other salmon farming regions around the world for monitoring sea lice sensitivity to therapeutic agents (Sevatdal \& Horsberg 2003, Sevatdal et al. 2005, Bravo et al. 2008). Westcott et al. (2008) examined Lepeophtheirus salmonis sensitivity to emamectin benzoate by bioassay from 2002 to early 2005 in samples collected in New Brunswick and found no changes between regions or over time by year. There were indications of decreased sensitivity of L. salmonis to emamectin benzoate during the fall and winter seasons. More recently, Igboeli et al. (2012) found increases in $\mathrm{EC}_{50}$ values from L. salmonis collected in 2011 compared with values obtained by Westcott et al. (2008) from 2002 to 2005 suggesting the development emamectin benzoate resistance had occurred over time.

In conclusion, this analysis presents evidence of a reduction in emamectin benzoate treatment effectiveness over time and between geographical locations for the period of time examined, 2004 to 2008. These results correspond with the clinical picture witnessed in the field of a decline in treatment effect, which became a concern in 2008 (Chang et al. 2011). Further investigation is warranted to confirm the underlying cause of this decline in treatment effectiveness. In addition, more collaboration is needed between laboratory investigations of sea lice sensitivity to treatment agents and epidemiological analyses of treatment events and sea lice trends, which would allow for a more holistic understanding of the development of parasiticide resistance in the aquatic environment.

Acknowledgements. The authors thank Drs. L. Hawkins and S. Fielding of Cooke Aquaculture along with Drs. M. Moore and D. MacPhee of Maritime Veterinary Services for kindly providing the data for this study. The authors also thank the Atlantic Innovation Fund and the provincial government partners (New Brunswick Department of Agriculture, Aquaculture, and Fisheries; Nova Scotia Department of Fisheries and Aquaculture; Prince Edward Island Department of Fisheries, Aquaculture and Rural Development; and Newfoundland and Labrador Department of Fisheries and Aquaculture) along with the Prince Edward Island Department of Innovation and Advanced Learning for providing the funding for this project. The map for Fig. 1 was kindly provided by B. Chang of Fisheries and Oceans Canada, St. Andrews Biological Station, New Brunswick.

\section{LITERATURE CITED}

Armstrong R, MacPhee D, Katz T, Endris R (2000) A field efficacy evaluation of emamectin benzoate for the control of sea lice on Atlantic salmon. Can Vet J 41:607-612

Boxaspen K (2006) A review of the biology and genetics of sea lice. ICES J Mar Sci 63:1304-1316

Bravo S, Sevatdal S, Horsberg TE (2008) Sensitivity assessment of Caligus rogercresseyi to emamectin benzoate in Chile. Aquaculture 282:7-12

Campbell PJ, Hammell KL, Dohoo IR, Ritchie G (2006) Randomized clinical trial to investigate the effectiveness of teflubenzuron for treating sea lice on Atlantic salmon. Dis Aquat Org 70:101-108 
Chang BD, Page FH, Beattie MJ, Hill BW (2011) Sea louse abundance on farmed salmon in the southwestern New Brunswick area of the Bay of Fundy. In: Jones S, Beamish $\mathrm{R}$ (eds) Salmon lice: an integrated approach to understanding parasite abundance and distribution. WileyBlackwell, Oxford, p 83-115

Costello MJ (2009) The global economic cost of sea lice to the salmonid farming industry. J Fish Dis 32:115-118

> Denholm I, Devine GJ, Horsberg TE, Sevatdal S, Fallang A, Nolan DV, Powell R (2002) Analysis and management of resistance to chemotherapeutants in salmon lice, Lepeophtheirus salmonis (Copepoda: Caligidae). Pest Manag Sci 58:528-536

Gustafson L, Ellis S, Robinson T, Marenghi F, Endris R (2006) Efficacy of emamectin benzoate against sea lice infestations of Atlantic salmon, Salmo salar L.: evaluation in the absence of an untreated contemporary control. J Fish Dis 29:621-627

Heuch PA, Gettinby G, Revie CW (2011) Counting sea lice on Atlantic salmon farms-empirical and theoretical observations. Aquaculture 320:149-153

Hogans WE (1995) Infection dynamics of sea lice, Lepeophtheirus salmonis, parasitic on Atlantic salmon (Salmo salar) culture in marine waters of the lower Bay of Fundy. Can Tech Rep Fish Aquat Sci 2067. Canada Department of Fisheries and Oceans, Ottawa

Hogans WE, Trudeau DJ (1989) Preliminary studies on the biology of sea lice, Caligus elongatus, Caligus curtus and Lepeophtheirus salmonis (Copepoda: Caligoida) parasitic on cage-cultured salmonids in the lower Bay of Fundy. Can Tech Rep Fish Aquat Sci 1715. Canada Department of Fisheries and Oceans, Ottawa

$>$ Horsberg TE (2012) Avermectin use in aquaculture. Curr Pharm Biotechnol 13:1095-1102

Igboeli OO, Fast MD, Heumann J, Burka JF (2012) Role of P-glycoprotein in emamectin benzoate (SLICE ${ }^{\circledR}$ ) resistance in sea lice, Lepeophtheirus salmonis. Aquaculture 344-349:40-47

Johnson SC, Albright LJ (1991a) The developmental stages of Lepeophtheirus salmonis (Kroyer, 1837) (Copepoda: Caligidae). Can J Zool 69:929-950

> Johnson SC, Albright LJ (1991b) Development, growth, and survival of Lepeophtheirus salmonis (Copepoda: Caligidae) under laboratory conditions. J Mar Biol Assoc UK 71:425-436

- Lees F, Baillie M, Gettinby G, Revie CW (2008a) The efficacy of emamectin benzoate against infestations of Lepeophtheirus salmonis on farmed Atlantic salmon (Salmo salar L) in Scotland, 2002-2006. PLoS One 3:e1549

> Lees F, Baillie M, Gettinby G, Revie CW (2008b) Factors associated with changing efficacy of emamectin benzoate against infestations of Lepeophtheirus salmonis on Scottish salmon farms. J Fish Dis 31:947-951

Lees F, Gettinby G, Revie CW (2008c) Changes in epidemiological patterns of sea lice infestation on farmed Atlantic salmon, Salmo salar L., in Scotland between 1996 and 2006. J Fish Dis 31:259-268

> Murray AG, Peeler EJ (2005) A framework for understanding the potential for emerging diseases in aquaculture. Prev Vet Med 67:223-235
O'Halloran J, Hogans WE (1996) First use in North America of azamethiphos to treat Atlantic salmon for sea lice infestation: procedures and efficacy. Can Vet J 37: 610-611

> Revie CW, Gettinby G, Treasurer JW, Wallace C (2005) Evaluating the effect of clustering when monitoring the abundance of sea lice populations on farmed Atlantic salmon. J Fish Biol 66:773-783

Revie CW, Hollinger E, Gettinby G, Lees F, Heuch PA (2007) Clustering of parasites within cages on Scottish and Norwegian salmon farms: alternative sampling strategies illustrated using simulation. Prev Vet Med 81:135-147

Robertsen B (2011) Can we get the upper hand on viral diseases in aquaculture of Atlantic salmon? Aquac Res 42: 125-131

Saksida S, Constantine J, Karreman GA, Donald A (2007) Evaluation of sea lice abundance levels on farmed Atlantic salmon (Salmo salar L.) located in the Broughton Archipelago of British Columbia from 2003 to 2005. Aquac Res 38:219-231

Saksida SM, Morrison D, Revie CW (2010) The efficacy of emamectin benzoate against infestations of sea lice, Lepeophtheirus salmonis, on farmed Atlantic salmon, Salmo salar L., in British Columbia. J Fish Dis 33:913-917

Schram TA (1993) Supplementary descriptions of the developmental stages of Lepeophtheirus salmonis (Kroyer, 1837) (Copepoda: Caligidae). In: Boxshall GA, Defaye DD (eds) Pathogens of wild and farmed fish: sea lice. Ellis Horwood, New York, NY, p 30-50

Sevatdal S, Horsberg TE (2003) Determination of reduced sensitivity in sea lice (Lepeophtheirus salmonis Krøyer) against the pyrethroid deltamethrin using bioassays and probit modelling. Aquaculture 218:21-31

- Sevatdal S, Copley L, Wallace C, Jackson D, Horsberg TE (2005) Monitoring of the sensitivity of sea lice (Lepeophtheirus salmonis) to pyrethroids in Norway, Ireland and Scotland using bioassays and probit modelling. Aquaculture 244:19-27

Stone J, Sutherland IH, Sommerville C, Richards RH, Endris RG (2000a) The duration of efficacy following oral treatment with emamectin benzoate against infestations of sea lice, Lepeophtheirus salmonis (Krøyer), in Atlantic salmon Salmo salar L. J Fish Dis 23:185-192

Stone J, Sutherland IH, Sommerville C, Richards RH, Varma KJ (2000b) Commercial trials using emamectin benzoate to control sea lice Lepeophtheirus salmonis infestations in Atlantic salmon Salmo salar. Dis Aquat Org 41: 141-149

Stone J, Sutherland IH, Sommerville C, Richards RH, Varma KJ (2000c) Field trials to evaluate the efficacy of emamectin benzoate in the control of sea lice, Lepeophtheirus salmonis (Krøyer) and Caligus elongatus Nordmann, infestations in Atlantic salmon Salmo salar L. Aquaculture 186:205-219

> Westcott JD, Stryhn H, Burka JF, Hammell KL (2008) Optimization and field use of a bioassay to monitor sea lice Lepeophtheirus salmonis sensitivity to emamectin benzoate. Dis Aquat Org 79:119-131

White HC (1940) 'Sea lice' (Lepeophtheirus) and death of salmon. J Fish Res Board Can 5a:172-175
Editorial responsibility: Stewart Johnson, Nanaimo, British Columbia, Canada
Submitted: March 15, 2012; Accepted: August 15, 2012

Proofs received from author(s): November 13, 2012 